\title{
Depigmenting Effect of Kojic Acid Esters in Hyperpigmented B16F1 Melanoma Cells
}

\author{
Ahmad Firdaus B. Lajis, ${ }^{1}$ Muhajir Hamid, ${ }^{2,3}$ and Arbakariya B. Ariff ${ }^{1,3}$ \\ ${ }^{1}$ Department of Bioprocess Technology, Faculty of Biotechnology and Biomolecular Sciences, \\ Universiti Putra Malaysia, 43400 Serdang, Malaysia \\ ${ }^{2}$ Department of Microbiology, Faculty of Biotechnology and Biomolecular Sciences, Universiti Putra Malaysia, \\ 43400 Serdang, Malaysia \\ ${ }^{3}$ Institute of Bioscience, Universiti Putra Malaysia, 43400 Serdang, Malaysia
}

Correspondence should be addressed to Arbakariya B. Ariff, arbarif@biotech.upm.edu.my

Received 14 May 2012; Revised 21 June 2012; Accepted 22 June 2012

Academic Editor: Kapil Mehta

Copyright (C) 2012 Ahmad Firdaus B. Lajis et al. This is an open access article distributed under the Creative Commons Attribution License, which permits unrestricted use, distribution, and reproduction in any medium, provided the original work is properly cited.

\begin{abstract}
The depigmenting effect of kojic acid esters synthesized by the esterification of kojic acid using Rhizomucor miehei immobilized lipase was investigated in B16F1 melanoma cells. The depigmenting effect of kojic acid and kojic acid esters was evaluated by the inhibitory effect of melanin formation and tyrosinase activity on alpha-stimulating hormone- ( $\alpha$-MSH-) induced melanin synthesis in B16F1 melanoma cells. The cellular tyrosinase inhibitory effect of kojic acid monooleate, kojic acid monolaurate, and kojic acid monopalmitate was found similar to kojic acid at nontoxic doses ranging from 1.95 to $62.5 \mu \mathrm{g} / \mathrm{mL}$. However, kojic acid monopalmitate gave slightly higher inhibition to melanin formation compared to other inhibitors at doses ranging from 15.63 to $62.5 \mu \mathrm{g} / \mathrm{mL}$. Kojic acid and kojic acid esters also show antioxidant activity that will enhance the depigmenting effect. The cytotoxicity of kojic acid esters in B16F1 melanoma cells was significantly lower than kojic acid at high doses, ranging from 125 and $500 \mu \mathrm{g} / \mathrm{mL}$. Since kojic acid esters have lower cytotoxic effect than kojic acid, it is suggested that kojic acid esters can be used as alternatives for a safe skin whitening agent and potential depigmenting agents to treat hyperpigmentation.
\end{abstract}

\section{Introduction}

Melanin is synthesized via melanogenesis process to give pigment of skin, brain, eye, and hair [1-3]. Tyrosinase is a key enzyme that is responsible for melanogenesis in melanoma and melanocytes $[4,5]$. The inhibition of tyrosinase will greatly affect the melanogenesis process and melanin production. The occurrence of abnormal melanin production is the cause for many hyperpigmentation, postinflammatory pigmentation, melasma, and skin-aging process [6-8]. Kojic acid is a well-known antityrosinase agent, efficiently used for skin lightening cosmetic products and widely used to treat hyperpigmentation, melasma, and wrinkle [5, 9-11]. However, most of the kojic acid and its derivatives are not oil soluble and unstable at high temperature for long term storage, prohibiting them to be directly incorporated in oil base cosmetic and skin-care products. Therefore, a few attempts had been made to improve the physical properties and biological activities of kojic acid (KA) via esterification with fatty acids aimed at better industrial application [12-14].

The physical properties of kojic acid esters (KA esters) are important factor for inhibition of melanin synthesis where it must penetrate into the cell membrane to inhibit cellular tyrosinase and melanin synthesis. Thus, appropriate hydrophobic and hydrophilic balance of the derivatives is important for the inhibition of melanin synthesis [15]. The improvements of the characteristics of depigmenting agents are very important to enhance their applications in cosmetic and skin-health industries. Reports on the antimelanin and tyrosinase inhibitory of KA esters in cell system are not available in the literature.

The objective of this study was to analyze the cytotoxicity and depigmenting activities of KA and KA esters such as KA monooleate (KAMO), KA monolaurate (KAML), and 
KA monopalmitate (KAMP) in B16F1 melanoma cells. KA was produced by the fermentation employing Aspergillus flavus link and KA esters were produced by the esterification of purified KA with various fatty acids using immobilized lipase.

\section{Materials and Methods}

2.1. Materials. Immobilized lipase from Rhizomucor miehei (RMIM) was purchased from Novo-Nordisk (Denmark). Dulbecco's modified Eagle's medium (DMEM), fetal bovine serum (FBS) penicillin, and streptomycin were purchased from Invitrogen (Grand Island, NY, USA). Glycerol tributyrate, L-dihydroxyphenylalanine (L-DOPA), L-tyrosine, mushroom tyrosinase, phenylmethanesulfonyl fluoride (PMSF), L-ascorbic acid, and alpha-melanocyte stimulating hormone $(\alpha-\mathrm{MSH})$ were purchased from Sigma-Aldrich (Steheim, UK). All other chemicals and solvents used in this study were the analytical grade.

2.2. Production of Kojic Acid. KA was produced through the fermentation by Aspergillus flavus link 44-1 according to the method as described by Mohamad and Ariff [16]. In this method, the fermentation medium consisted of glucose $(100 \mathrm{~g} / \mathrm{L})$, yeast extract $(5 \mathrm{~g} / \mathrm{L})$, potassium dihydrogen phosphate $(1 \mathrm{~g} / \mathrm{L})$, magnesium sulphate $(0.5 \mathrm{~g} / \mathrm{L})$, and methanol $(10 \mathrm{~mL} / \mathrm{L})$. The fungal spores suspension $\left(1 \times 10^{5}\right.$ spores/ $\mathrm{mL}$ ) was inoculated into $100 \mathrm{~mL}$ medium in $250 \mathrm{~mL}$ shakeflasks. The flasks were incubated at $30^{\circ} \mathrm{C}$ and agitated at $250 \mathrm{rpm}$ for 5 days. The mycelia were filtered, washed, and transferred into $200 \mathrm{~mL}$ medium containing $100 \mathrm{~g} / \mathrm{L}$ glucose in $500 \mathrm{~mL}$ shake flasks. The flasks were incubated in an orbital shaker at $30^{\circ} \mathrm{C}$ and agitated at $250 \mathrm{rpm}$ for 30 days for the conversion of glucose into KA by the actions of cellbound enzymes in nongrowing mycelia.

Cell mycelia were separated from the broth by centrifugation at $10000 \mathrm{~g}$ (GRX-250, Tomy Seiko Co., Ltd. Japan). The supernatant containing KA was concentrated to get a final KA concentration of above $80 \mathrm{~g} / \mathrm{L}$ using rotary evaporator (BUCHI model R-220, Germany). The concentrated KA solution was kept at $30^{\circ} \mathrm{C}$ for $24 \mathrm{~h}$ for crystallization. The KA crystals were separated by centrifugation and redisolved in methanol for the subsequent crystallization process to remove further pigments and impurities. High-purity KA $(99.8 \%)$ was obtained after recrystallization with methanol for three times.

2.3. Enzymatic Synthesis of Kojic Acid Esters. The esterification of KA to KA esters (KAMO, KAML, and KAMP) was performed according to the method previously described $[12,17]$. The reaction mixture for esterification process consisted of fatty acids (oleic acid, lauric acid, and palmitic acid), $\mathrm{KA}$, and immobilized lipase in acetonitrile. The flasks containing the reaction mixture were incubated in a horizontal water bath shaker at $50^{\circ} \mathrm{C}$, agitated at $180 \mathrm{rpm}$ for $42 \mathrm{~h}$. The reaction was terminated, by removing the enzyme from the mixture through filtration using filter paper. KA esters were purified using crystallization method similar to that used for KA.

KA esters were examined by thin layer chromatography (TLC) on precoated silica gel plate $\left(60 \mathrm{~F}_{254}\right)$ and developed in hexane/ethyl acetate $(70: 30, \mathrm{v} / \mathrm{v})$. The developed bands were visualized using UV light. Then, the products were analyzed on Agilent gas chromatograph after being silylated to TMS derivatives using a nonpolar column ZB-5HT Inferno $(15 \mathrm{~m} \times 0.53 \mathrm{~mm} \times 0.15 \mu \mathrm{m})$ with nitrogen as carrier gas. The oven temperature was programmed to rise from $100^{\circ} \mathrm{C}$ to $225^{\circ} \mathrm{C}$ at $15^{\circ} \mathrm{C} \mathrm{min}^{-1}$, and to $280^{\circ} \mathrm{C}$ at $30^{\circ} \mathrm{C} \mathrm{min}^{-1}$ for $1 \mathrm{~min}$. The injector and flame ionization detectors were set at $340^{\circ} \mathrm{C}$, and $350^{\circ} \mathrm{C}$ respectively. The composition of product was quantified by an integrator with 1,2,3-tributyrylglycerol as internal standard.

2.4. Characterization of KA Esters. The GC-mass spectrometry (GC-MS) analysis of the product isolated using preparative column chromatography was performed on a Perkin Elmer Instrument model Clarus 600 MS spectrometer. The GC was equipped with a non-polar column, ZB5HT $(30 \mathrm{~m} \times 0.32 \mathrm{~mm} \times 0.25 \mu \mathrm{m})$. The carrier gas was helium at a flow rate of $1.5 \mathrm{~mL} \mathrm{~min}^{-1}$. Proton NMR $(1 \mathrm{H}-$ NMR) and carbon NMR (13C-NMR) spectra were obtained using Varian NMR Unity Inova $500 \mathrm{MHz}$ with Pulsed Field Gradient. The samples were dissolved in deuterated chloroform with tetramethylsilane as internal standard. On the other hand, FTIR spectra were recorded on a Perkin Elmer 100-series FTIR spectrophotometer using Universal Attenuated Total Reflectance (UATR). The IR spectra were used to identify the possible molecular structures for the pure components and also used to determine the chemical changes during the reaction.

2.5. Cell Culture. B16F1 melanoma cells were purchased from American Type Culture Collection (ATCC). The cells were cultured in DMEM with $10 \% \mathrm{w} / \mathrm{v}$ fetal bovine serum and $1 \% \mathrm{w} / \mathrm{v}$ penicillin/streptomycin $(100 \mathrm{IU} / 50 \mu \mathrm{g} / \mathrm{mL})$ in humidified atmosphere containing $5 \% \mathrm{CO}_{2}$ in air at $37^{\circ} \mathrm{C}$. B16 cells were cultured in 96-well plates and 24-wells plates for different assays. All the experiments were repeated at least in triplicates.

2.6. Determination of Cell Viability. Cell viability was assessed by the standard MTT (3-(4,5-dimethylthiazol-2-yl)2,5-diphenyltetrazolium bromide) assay with a slight modification [18]. B16F1 melanoma cells $\left(1 \times 10^{5}\right.$ cells/well $)$ were seeded in a 96-well microtiter plate and allowed to adhere completely to the plate overnight [19]. On the next day, the medium was removed and a new medium containing test compounds with doses ranging from 1.9 to $500 \mu \mathrm{g} / \mathrm{mL}$ was added to the plate and then incubated at $37^{\circ} \mathrm{C}$ in $\mathrm{CO}_{2}$ incubator. After a total of $72 \mathrm{~h}$ incubation, medium was removed and $50 \mu \mathrm{L}$ of MTT solutions $(1.0 \mathrm{mg} / \mathrm{mL})$ was added to each well and the incubation was continued for $4 \mathrm{~h}$. Then, formazon was solubilized in dimethyl sulfoxide (DMSO) and the absorbance was measured at $450 \mathrm{~nm}$ (reference at $630 \mathrm{~nm}$ ) 
using MR-96A microplate reader. DMSO at a toxic concentration of $5 \% \mathrm{v} / \mathrm{v}$ was used as a negative control [20].

2.7. Determination of Melanin Content. The release of extracellular melanin was measured according to the method described elsewhere [21]. In brief, B16F1 melanoma cells were seeded into 24 -wells tissue culture plates at $1 \times 10^{4}$ cells/ $\mathrm{mL}$ and incubated for $24 \mathrm{~h}$. Then, alpha-MSH $(0.1 \mu \mathrm{M})$ was added and cells were treated with increasing doses of KA and KA esters for a total of $72 \mathrm{~h}$ incubation. After washing twice with phosphate buffered saline, cells were dissolved in $1 \mathrm{~mL}$ of $1 \mathrm{~N} \mathrm{NaOH}$. For measurement of melanin content, $100 \mu \mathrm{L}$ aliquots of solution were then placed in 96-well plates and the absorbance was measured at $450 \mathrm{~nm}$ using microplate reader. Antimelanin activity was expressed by the percentage of melanin content in KA and KA esters to that of untreated melanoma cells. L-ascorbic acid, a widely used whitening agent, was used as a reference [22].

2.8. Determination of Cellular Tyrosinase Activity. Cellular tyrosinase activity was determined according to the method described by Shin et al. [23]. In this method, B16F1 melanoma cells were treated with $\alpha$-MSH alone and $\alpha$-MSH with the addition of KA and KA esters at various doses for a total of $72 \mathrm{~h}$ incubation. The cells were washed with ice-cold PBS then lysed with $100 \mu \mathrm{L}$ phosphate buffer (pH 6.8) containing $1 \%$ Triton X-100 and $0.1 \mathrm{mM}$ phenylmethylsulfonyl fluoride (PMSF). Then, lysate was clarified by centrifugation at $800 \mathrm{rpm}$ for $5 \mathrm{~min}$. The supernatant $(100 \mu \mathrm{L})$ was added into $50 \mu \mathrm{L}$ of L-DOPA $(1 \mathrm{mM})$ and $50 \mathrm{uL}$ of L-Tyrosine $(2 \mathrm{mM})$; and the mixtures were placed in a 96-well plate. During the incubation at $37^{\circ} \mathrm{C}$, the absorbance was read at $492 \mathrm{~nm}$ at every $30 \mathrm{~min}$ for $3 \mathrm{~h}$ using a microplate reader. Lascorbic acid was used as a reference.

2.9. Determination of Mushroom Tyrosinase Activity. KA and KA esters at various doses were dissolved in DMSO, $50 \mu \mathrm{L}$ of L-DOPA $(1 \mathrm{mM})$ and $50 \mu \mathrm{L}$ of L-tyrosine $(2 \mathrm{mM})$, dissolved in $20 \mathrm{mM}$ phosphate buffer (pH 6.8). DMSO or test sample $(50 \mu \mathrm{L})$ was added into these mixtures in a 96-well microplate, followed by mixing with $50 \mu \mathrm{L}$ of mushroom tyrosinase solution ( 480 units $/ \mathrm{mL}$ ). After incubation at $25^{\circ} \mathrm{C}$ for $10 \mathrm{~min}$, the amount of dopachrome in the reaction mixture was determined. The inhibitory activity of the sample was expressed as percentage to control based on the absorbance measured at $492 \mathrm{~nm}[6]$.

2.10. Determination of Free Radical Scavenging Activity. The effect of KA and KA esters on the free radical scavenging 2,2diphenyl-1-picrylhydrazyl (DPPH) activities was estimated on a 96-well plate [18]. Test compounds $(100 \mu \mathrm{L})$ dissolved in dimethyl sulfoxide solutions were added into $100 \mu \mathrm{L}$ of $0.2 \mathrm{mM}$ DPPH in ethanol. $100 \mu \mathrm{L}$ of dimethyl sulfoxide solution alone was added into $100 \mu \mathrm{L}$ of $0.2 \mathrm{mM} \mathrm{DPPH}$ in ethanol as blank. The plates were incubated at $25^{\circ} \mathrm{C}$ for
$30 \mathrm{~min}$ and the absorbance was read at $492 \mathrm{~nm}$. The percentage of antioxidative activity was calculated according to (1),

Percentage of antioxidative activity

$$
\begin{aligned}
= & {\left[\frac{\text { absorbance of control }- \text { absorbance of test compound }}{\text { absorbance of control }}\right] } \\
& \times 100 \text {. }
\end{aligned}
$$

DPPH is a stable free radical with violet colour. It turns to yellow in the presence of antioxidant and scavenging agents.

2.11. Statistical Analysis. Data were collected as mean \pm standard error (S.E.M) of at least three determinations. Statistical analysis was performed using Microsoft Excel 2007 (Microsoft, WA, USA). The evaluation of statistical significance was performed by Student $t$-test (two-tailed). $P<0.05$ was considered statistically significant, $n \geq 3,[2,21,24-28]$.

\section{Results}

3.1. Production of Kojic Acid Esters. The maximum yield of KA esters synthesized by enzymatic esterification using immobilized lipase is shown in Table 1. The structure of KAMO has been identified and characterized in our previous study $[12,17]$. The yield for KAMO, KAML, and KAMP was $32.86 \%, 34.89 \%$, and $29.30 \%$, respectively. The time taken to reach a maximum KAMO, KAML, and KAMP concentration was $42 \mathrm{~h}, 15 \mathrm{~h}$, and $12 \mathrm{~h}$, respectively. Meanwhile, KAML and KAMP were identified using GC-MS where the purified samples were fragmented to simple ions. The MS data for the esterification of KA and palmitic acid showed that ions at $\mathrm{m} / \mathrm{z}$ 141 and 365 arise from path a and b cleavage. The $m / z 363$ is the expected rearrangement ion resulting path c cleavage with loss of $\mathrm{OH}(\mathrm{m} / z 480-17)$. The fragmentation at $\mathrm{m} / \mathrm{z}$ 255 and 125 confirm path $d$ and e cleavage. The product of the esterification, KAMP, is shown at $m / z$ 380. Meanwhile, the MS data for the esterification of KA and lauric acid showed that ions at $m / z 141$ and 309 arise from path $\mathrm{a}$ and $\mathrm{b}$ cleavage. The $\mathrm{m} / z 307$ is the expected rearrangement of ion resulting to path $c$ cleavage with loss of $\mathrm{OH}(\mathrm{m} / z$ 480-17). The fragmentation at $m / z 199$ and 125 confirm path $\mathrm{d}$ and e cleavage. The fragmentation at $\mathrm{m} / z 197$ is the expected ion from path $\mathrm{f}$ cleavage. The data for esterification reaction of KA also showed that ions at $m / z 142$. The esterification product, KAML, is shown at $m / z 324$ (Figure 1 ).

The $1 \mathrm{H}-\mathrm{NMR}$ spectrum of the KAMP and KAML gave 3 -hydrogen triplet at $\delta 0.88$, indicating a terminal methyl group. Two hydrogen methylene signals are observed at $\mathrm{H}^{\prime}{ }^{-}$ $\mathrm{H}^{1} 5^{\prime}$ and $\mathrm{H} 3^{\prime}-\mathrm{H} 11^{\prime}$ of KAMP and KAML, respectively. The downfield methylene signal at $\delta 2.40$ was due to the present of $\mathrm{CH}_{2}$ group, next to the ester linkage. The fatty acid chain was thus established to be present in the product. The KA portion of the molecule was confirmed by the presence of two singlet signals at $\delta 6.49$ and $\delta 7.85$ which were assigned to $\mathrm{H}-3$ and $\mathrm{H}-6 . \mathrm{H}-7$ gave a singlet signal at $\delta 4.93$. The $13 \mathrm{C}-$ NMR spectrum gave a total carbon count for KAMP and KAML of 22 and 18, respectively. The C-1' (ester group) peak 
TABLE 1: The yield of KA esters synthesized by enzymatic esterification using immobilized lipase from Rhizomucor miehei at optimal reaction condition.

\begin{tabular}{|c|c|c|c|c|c|}
\hline \multirow{2}{*}{ Compound } & \multicolumn{4}{|c|}{ Variables } & \multirow{2}{*}{ Yield $(\%)$} \\
\hline & *Time $(\mathrm{h})$ & Temperature $\left({ }^{\circ} \mathrm{C}\right)$ & Enzyme (g) & Substrate molar ratio $(\mathrm{mmol})$ & \\
\hline KAMO & 42 & 52.5 & 0.33 & 0.5 & 32.86 \\
\hline KAML & 15 & 50.0 & 0.20 & 5 & 34.89 \\
\hline KAMP & 12 & 50.0 & 0.20 & 5 & 29.30 \\
\hline
\end{tabular}

*A time of enzymatic esterification to achieve maximum concentration of KA esters.

Percentage yield was calculated using following equation:

Yield $(\%)=\left(C_{\text {comp }} /\right.$ mole of KA $) \times$ dilution factor $\times 100$

$C_{\text {comp }}=\left(A_{\text {comp }} / A_{\mathrm{IS}}\right) \times\left(C_{\mathrm{IS}} / D_{\mathrm{RF}}\right)$,

where, $A_{\text {comp }}$ : area for each component; $A_{\mathrm{IS}}$ : area for internal standard; CIS: concentration for internal standard; $D_{\mathrm{RF}}: D_{\mathrm{RF}}$ standard $/ D_{\mathrm{RF}}$ internal standard; $C_{\text {comp }}$ : concentration for each component.<smiles>O=c1cc(CO)occ1O</smiles>

Kojic acid [11]<smiles>CCCCCCCC/C=C/CCCCCCCC(=O)Oc1coc(CO)cc1=O</smiles>

Kojic acid monooleate $[12,17]$

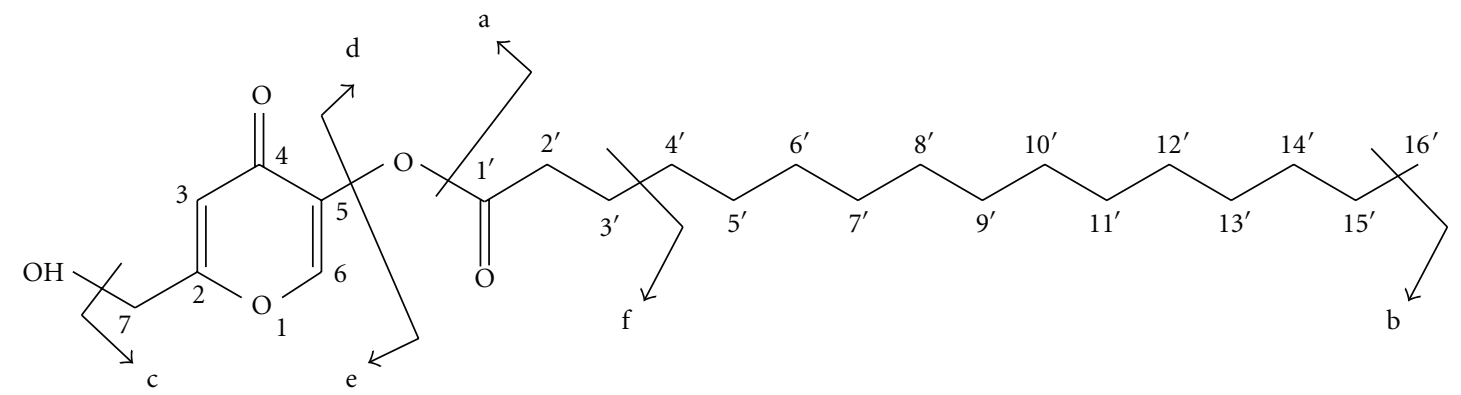

Kojic acid monopalmitate

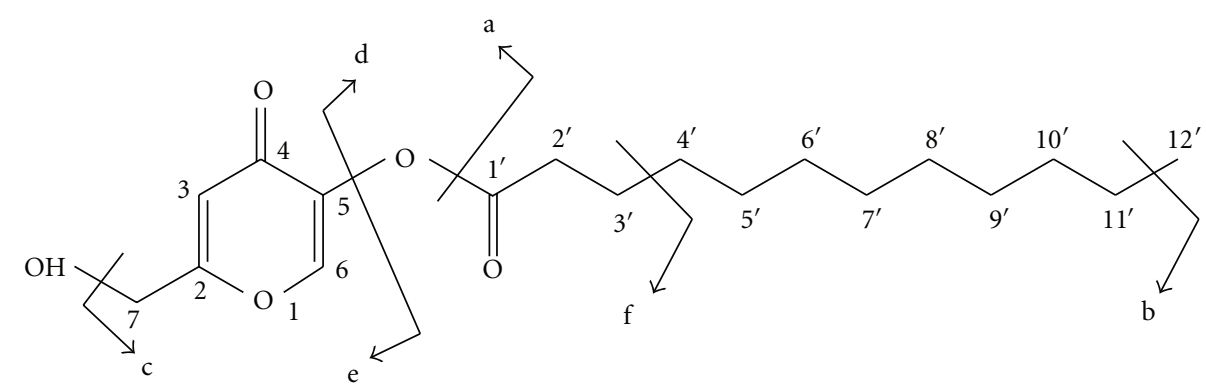

Kojic acid monolaurate

Figure 1: Chemical structure of kojic acid (KA), kojic acid monoeolate (KAMO), kojic acid monopalmitate (KAMP) and kojic acid monolaurate (KAML). 
appeared at 163 . Very low field signals were observed at $\delta 172$ and $\delta 173$ which were due to C-2 and C- 4 of the pyrone ring. The other carbon assignments are also shown in Table 2.

The product formation and reactant disappearance were monitored by IR spectroscopy. The infrared spectrum of the KAMP showed the stretching of $\mathrm{CH}_{2}$ and $\mathrm{CH}_{3}$ which gave absorption peaks at $2848 \mathrm{~cm}^{-1}$ and $2914 \mathrm{~cm}^{-1}$, respectively. The $\mathrm{C}=\mathrm{O}$ stretching for the expected ester carbonyl gave an absorption peak at $1695 \mathrm{~cm}^{-1}$. The present of aromatic ring gave absorption at $1619 \mathrm{~cm}^{-1}$. The $\mathrm{CH}_{2}$ and $\mathrm{CH}_{3}$ bends showed absorptions at $1458 \mathrm{~cm}^{-1}$ and $1290 \mathrm{~cm}^{-1}$. Meanwhile, $\mathrm{O}=\mathrm{C}-\mathrm{O}$ stretching absorbed at $1109 \mathrm{~cm}^{-1}$. On the other hand, the infrared spectrum of the KAML showed the stretching of $\mathrm{CH}_{2}$ and $\mathrm{CH}_{3}$ which gave absorption peaks at $2849 \mathrm{~cm}^{-1}$ and $2915 \mathrm{~cm}^{-1}$, respectively. The $\mathrm{C}=\mathrm{O}$ stretching for the expected ester carbonyl gave an absorption peak at $1693 \mathrm{~cm}^{-1}$. The present of aromatic ring gave absorption at $1616 \mathrm{~cm}^{-1}$. The $\mathrm{CH}_{2}$ and $\mathrm{CH}_{3}$ bends showed absorptions at $1427 \mathrm{~cm}^{-1}$ and $1292 \mathrm{~cm}^{-1}$, respectively. Meanwhile, $\mathrm{O}=\mathrm{C}-\mathrm{O}$ stretching absorbed at $1138-11073 \mathrm{~cm}^{-1}$.

3.2. Cytotoxicity Effect of KA and KA Esters. The results of cell viability assay using MTT in B16F1 melanoma cells are shown in Figure 2. There was no significant reduction of cell viability after incubation of pigmented B16F1 melanoma cells with KAMO, KAML, KAMP and KA at doses ranging from $7.81 \mu \mathrm{g} / \mathrm{mL}$ to $31.25 \mu \mathrm{g} / \mathrm{mL}$. However, the number of viable cells was significantly reduced to below $60 \%$ at KA concentration of $125 \mu \mathrm{g} / \mathrm{mL}$ and $500 \mu \mathrm{g} / \mathrm{mL}$. On the other hand, even at very high dosages of KAMO and KAMP ranging from 125 to $500 \mu \mathrm{g} / \mathrm{mL}$, more than $90 \%$ of B16F1 melanoma cells were still viable. Meanwhile, it was also noted that the number of viable cells was significantly reduced at $5 \%$ of DMSO which was used as a negative control.

\subsection{Inhibitory Effect of KA and KA Esters on Melanin Content.} The inhibitory effect of KA and KA esters on melanin formation in B16F1 melanoma cells treated with $\alpha$-MSH is summarized in Figure 3. The inhibitory effect of KAMO, KAML, KAMP, and KA was evaluated at nontoxic doses ranging from 1.95 to $62.5 \mu \mathrm{g} / \mathrm{mL}$. The melanin content was significantly reduced at KA and KA esters concentration ranging from 31.3 to $62.5 \mu \mathrm{g} / \mathrm{mL}$. KA and KA esters showed similar melanin inhibitory effect at the lowest dose tested in this study $(1.95 \mu \mathrm{g} / \mathrm{mL})$. Even at the highest dose tested, KAML was found to have similar melanin inhibitory effect to KA. However, KAMP have slightly higher inhibitory effect than other compounds tested at doses ranging from $15.63 \mu \mathrm{g} /$ $\mathrm{mL}$ to $62.5 \mu \mathrm{g} / \mathrm{mL}$.

3.4. Inhibitory Effect of KA and KA Esters on Cellular and Mushroom Tyrosinase Activity. The inhibitory effect of KA and $\mathrm{KA}$ esters in $\mathrm{B} 16 \mathrm{~F} 1$ melanoma cells is summarized in Figure 4. The inhibitory effect of KA and KA esters was evaluated at nontoxic doses, ranging from 1.95 to $62.5 \mu \mathrm{g} / \mathrm{mL}$. Incubation of pigmented melanoma B16F1 melanoma cells with $\mathrm{KA}$ and $\mathrm{KA}$ esters at doses ranging from $31.25 \mu \mathrm{g} / \mathrm{mL}$ to
TABLE $2:{ }^{1} \mathrm{H}-\mathrm{NMR}$ and ${ }^{13} \mathrm{C}-\mathrm{NMR}$ data for KAMP and KAML.

\begin{tabular}{|c|c|c|c|c|}
\hline \multirow[b]{2}{*}{ Carbon no. } & \multicolumn{2}{|c|}{ KAMP } & \multicolumn{2}{|c|}{ KAML } \\
\hline & $\delta^{1} \mathrm{H}$ & $\delta{ }^{13} \mathrm{C}$ & $\delta{ }^{1} \mathrm{H}$ & $\delta^{13} \mathrm{C}$ \\
\hline $\mathrm{C}-2$ & - & 172.69 & - & 172.69 \\
\hline $\mathrm{C}-3$ & $6.49(\mathrm{~s})$ & 110.99 & $6.49(\mathrm{~s})$ & 110.94 \\
\hline C-4 & - & 173.85 & - & 173.82 \\
\hline C-5 & - & 137.75 & - & 137.67 \\
\hline C-6 & $7.85(\mathrm{~s})$ & 145.80 & $7.85(\mathrm{~s})$ & 145.77 \\
\hline $\mathrm{C}-7$ & $4.93(\mathrm{~s})$ & 61.13 & $4.93(\mathrm{~s})$ & 61.13 \\
\hline C-1'ester group & - & 163.11 & - & 163.13 \\
\hline $\mathrm{C}-2^{\prime}$ & $2.40(\mathrm{t})$ & 33.88 & $2.40(\mathrm{t})$ & 33.88 \\
\hline $\mathrm{C}-3^{\prime}$ & $1.66(\mathrm{~m})$ & 24.77 & $1.64(\mathrm{~m})$ & 24.77 \\
\hline$C-4^{\prime}$ & 1.29 & 29.18 & 1.28 & 29.18 \\
\hline$C-5^{\prime}$ & 1.29 & 29.34 & 1.28 & 29.23 \\
\hline$C-6^{\prime}$ & 1.29 & 29.41 & 1.28 & 29.30 \\
\hline $\mathrm{C}-7^{\prime}$ & 1.29 & 29.56 & 1.28 & 29.41 \\
\hline $\mathrm{C}-8^{\prime}$ & 1.29 & 29.64 & 1.28 & 29.56 \\
\hline C-9' & 1.29 & 29.65 & 1.28 & 29.06 \\
\hline C-10' & 1.29 & 29.67 & 1.28 & 31.89 \\
\hline $\mathrm{C}-11^{\prime}$ & 1.29 & 29.67 & 1.30 & 22.66 \\
\hline C-12' & 1.29 & 29.64 & $0.88(\mathrm{t})$ & 14.09 \\
\hline C-13' & 1.29 & 29.06 & & \\
\hline C-14' & 1.29 & 31.91 & & \\
\hline C-15' & 1.30 & 22.67 & & \\
\hline$C-16^{\prime}$ & $0.88(\mathrm{t})$ & 14.09 & & \\
\hline
\end{tabular}

$62.5 \mu \mathrm{g} / \mathrm{mL}$ showed significant reduction in cellular tyrosinase activity. At very low doses of KA and KA esters, ranging from 1.95 to $15.25 \mu \mathrm{g} / \mathrm{mL}$, only a slight reduction in cellular tyrosinase activity was observed. The inhibitory effect of KA and KA esters on cellular tyrosinase activity at doses ranging from 31.25 to $62.5 \mu \mathrm{g} / \mathrm{mL}$ was not significantly different. At the same dose $(15.63 \mu \mathrm{g} / \mathrm{mL})$, KAML and KAMP reduced cellular tyrosinase activity at a greater extent than KAMO.

Inhibitory effect of KA and KA esters on mushroom tyrosinase activity is illustrated in Figure 5. The inhibitory effect of KA and KA esters was evaluated at doses ranging from 3.91 to $250 \mu \mathrm{g} / \mathrm{mL}$. In this study, mushroom tyrosinase inhibitory was found to be in dose-dependent manner. Among KA esters, KAMO significantly inhibited mushroom tyrosinase superior than KAML and KAMP. The inhibitory effect of mushroom tyrosinase activity of KAMO was not significantly different to KA at doses ranging from 62.5 to $250 \mu \mathrm{g} / \mathrm{mL}$.

3.5. The Antioxidant Activity of KA and KA Esters. The correlation between antimelanogenic activity with oxidative properties of KA and KA esters was also investigated. KA and KA esters showed mild free radical scavenging activity at concentrations ranging from 1.95 to $1000 \mu \mathrm{g} / \mathrm{mL}$ (Table 3). 2,2diphenyl-1-picrylhydrazyl (DPPH) generation was inhibited by KA and KA esters in dose dependent manner. Among them, KA and KAMO showed slightly better antioxidant activity at higher doses $(1000 \mu \mathrm{g} / \mathrm{mL})$ as compared to KAML and KAMP. L-ascorbic acid, a well-known antimelanogenic 


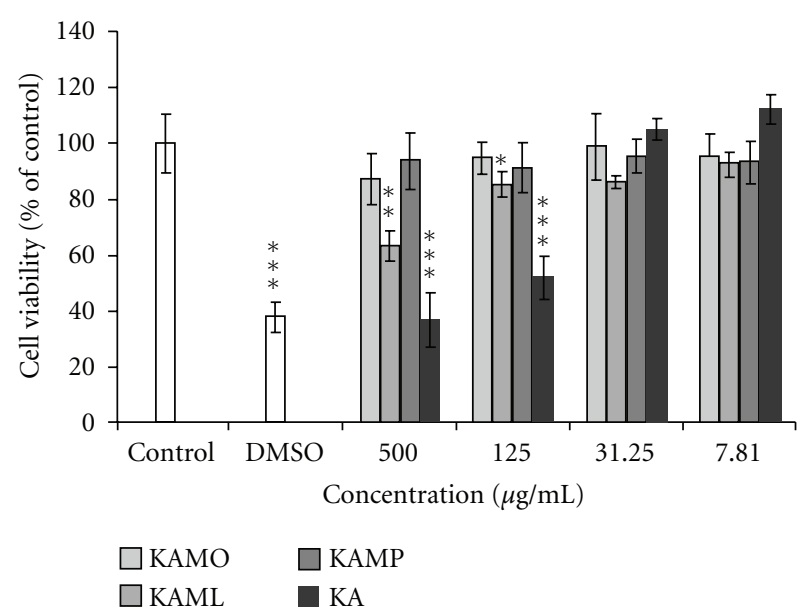

FIgURE 2: The effects of KAMO, KAML, KAMP, and KA on the viability of B16F1 melanoma cells. DMSO (5\%) was used as a negative control. Cells were treated with various doses of KAMO, KAML, KAMP, and KA $(7.81-500 \mu \mathrm{g} / \mathrm{mL})$ for a total of $72 \mathrm{~h}$ incubation and were examined by MTT assay. Denotes ${ }^{*} P<0.05$, ${ }^{* *} P<0.01$, ${ }^{* * *} P<0.001$ compared to untreated control. Data are presented as means \pm S.E.M and expressed as $\%$ of control, $n \geq 3$.

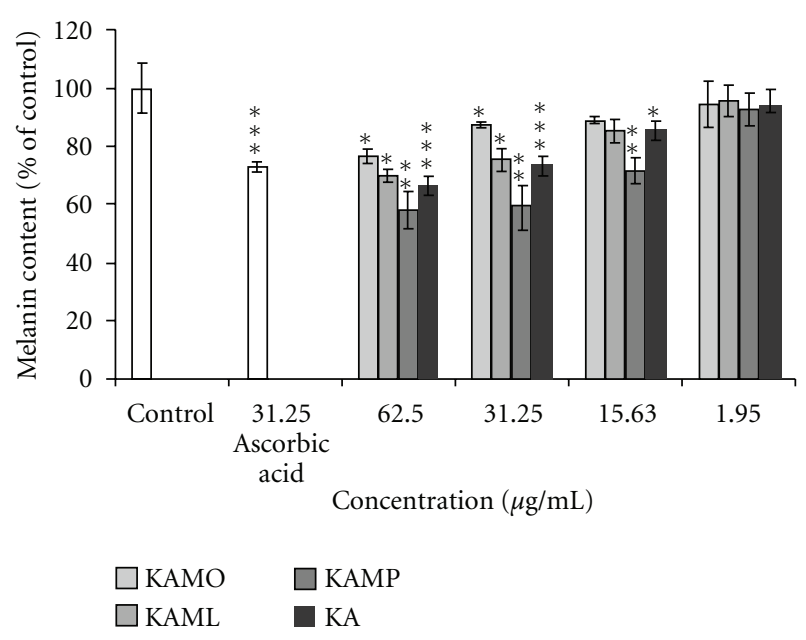

Figure 3: The effects of KAMO, KAML, KAMP, and KA on melanin content in B16F1 melanoma cells. Denotes ${ }^{*} P<0.05$, ** $P<$ $0.01,{ }^{* * *} P<0.001$ compared to $\alpha$-MSH treated control. Data are presented as means \pm S.E.M, and expressed as \% of control. $31.25 \mu \mathrm{g} / \mathrm{mL}$ ascorbic acid was used as reference. $n \geq 3$.

vitamin and antioxidant, exerted more scavenging activity than KA and KA esters at $62.5 \mu \mathrm{g} / \mathrm{mL}$.

\section{Discussion}

B16F1 melanoma cells is a widely used model to evaluate depigmentation activity with high level of tyrosinase and melanin content as compared to B16F10, due to high level of msg1 (melanocyte-specific gene) [22, 24, 28-33]. In melanogenesis, tyrosinase-related protein-2 and tyrosinase-related protein-1 catalyzes conversion of DOPachrome to DHICA
TABLE 3: Antioxidant effects of KA, KAMP, KAML and KAMO using DPPH. Denotes ${ }^{*} P<0.05,{ }^{* *} P<0.01,{ }^{* * *} P<0.001$ compared to untreated control. Data are presented as means \pm S.E.M, and expressed as $\%$ of control, $n \geq 3$.

\begin{tabular}{lcc}
\hline Sample & Concentration $(\mu \mathrm{g} / \mathrm{mL})$ & $\begin{array}{c}\text { Scavenging activity } \\
\text { \% of control }) \text { S.E.M }\end{array}$ \\
\hline Control & 0 & $0.06 \pm 0.06$ \\
\hline \multirow{3}{*}{ KA } & 1.95 & $5.86 \pm 0.28^{* * *}$ \\
& 62.5 & $29.24 \pm 4.18^{*}$ \\
& 250 & $46.73 \pm 5.21^{*}$ \\
KAMP & 1000 & $57.07 \pm 1.64^{* * *}$ \\
\hline & 1.95 & $3.00 \pm 0.40^{*}$ \\
KAML & 62.5 & $4.69 \pm 0.34^{* *}$ \\
& 250 & $9.41 \pm 3.43$ \\
& 1000 & $53.05 \pm 13.47^{*}$ \\
\hline \multirow{3}{*}{ KAMO } & 1.95 & $3.28 \pm 3.14$ \\
& 62.5 & $11.96 \pm 9.61$ \\
& 250 & $16.91 \pm 5.06$ \\
L-ascorbic & 1000 & $44.70 \pm 6.66^{*}$ \\
\hline
\end{tabular}

and oxidation of DHICA, respectively, to form melanin [34]. In the presence of alpha-melanocyte stimulating hormone $(\alpha-\mathrm{MSH})$, and isobutylmethylxanthine (IBMX), B16 melanoma cells expressed great amount of tyrosinase and melanin synthesis $[10,31]$. $\alpha$-MSH binds to melanocortin receptor (MC1R), resulting in the activation of stimulatory GTP-binding protein (Gs), which in turn, stimulates adenylate cyclase to generate cAMP. cAMP increases melanin synthesis via activation of cAMP-dependent protein kinase (PKA) and microphthalmia-associated transcription factor (MITF), a melanocyte-specific transcription factor, leading to induction of tyrosinase expression [35-38]. Hyperpigmentation and melasma are the result from the accumulation of tyrosinase and melanin in cells. Therefore, the ability of KAMO, KAML, and KAMP to inhibit tyrosinase activity and melanin content in alpha-MSH induced B16F1 melanoma cells showed their potential as depigmenting agent and to treat hyperpigmentation in vitro.

Melanin synthesis can also be induced by the presence of free radicals and reactive species. Excessive explore of ultraviolet radiation, metal ions, free radicals, and reactive species have significantly stimulate transcription of tyrosinase gene and contribute to hyperpigmentation $[4,39]$. The presence of metal ions, free radical, and reactive species caused oxidation in melanogenesis pathway that will result in high melanin synthesis [8]. Antioxidant such as vitamin C and multivitamin were known to scavenge free radicals and inhibit tyrosinase activity [40]. The stable DPPH free radicals are a commonly use model and technique to evaluate antioxidant activities. The effect of antioxidants on DPPH free radicals was due to their hydrogen donating ability. DPPH free radicals accept electron or hydrogen radicals to become 


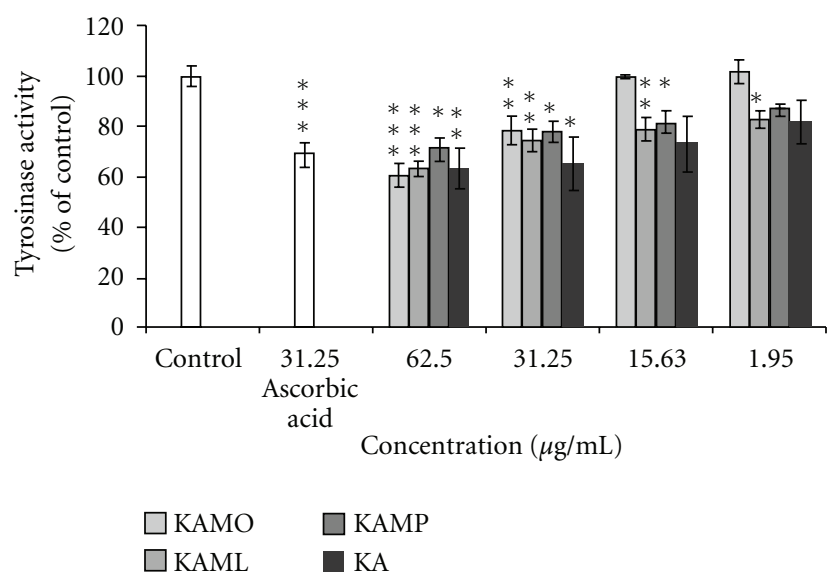

FIGURE 4: The results of the inhibition of tyrosinase activity by KAMO, KAML, KAMP, and KA in B16F1 melanoma cells. Denotes ${ }^{*} P<0.05,{ }^{* *} P<0.01,{ }^{* * *} P<0.001$ compared to $\alpha$-MSH treated control. Data are presented as means \pm S.E.M, and expressed as $\%$ of control. $31.25 \mu \mathrm{g} / \mathrm{mL}$ ascorbic acid was used as reference. $n \geq 3$.

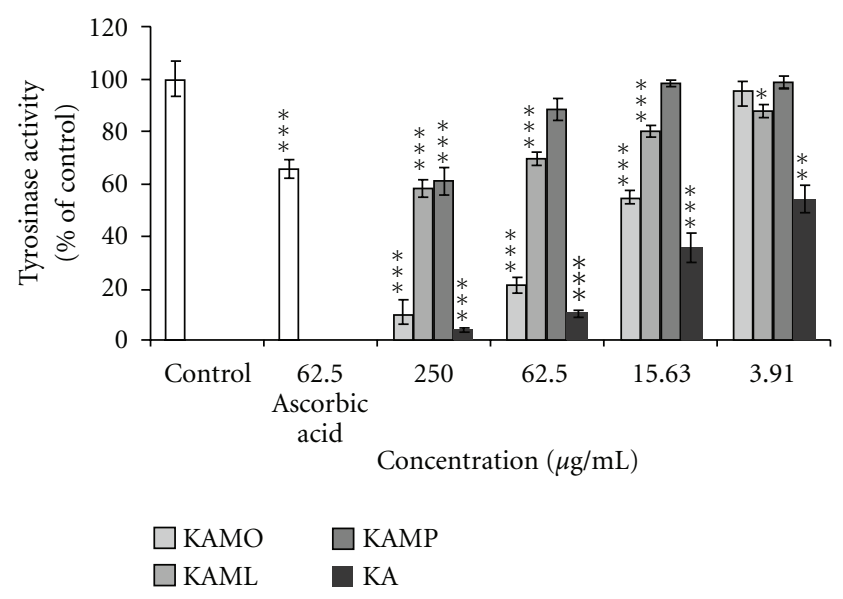

FIGURE 5: The results of the inhibition of mushroom tyrosinase activity by KAMO, KAML, KAMP, and KA. Denotes ${ }^{*} P<0.05$, ${ }^{* *} P<0.01,{ }^{* * *} P<0.001$ compared to $\alpha$-MSH treated control. Data are presented as means \pm S.E.M, and expressed as $\%$ of control. $62.5 \mu \mathrm{g} / \mathrm{mL}$ ascorbic acid was used as reference. $n \geq 3$.

stable diamagnetic molecules. The decrease in absorbance of DPPH radical caused by antioxidants, because of the reaction between antioxidant molecules and radical progresses, which results in the scavenging of the radical by hydrogen donation [41]. Therefore, the potency of hydroxyl group $(\mathrm{OH})$ at C-7 of KA esters to stabilize free radicals and chelate metal ions [9] may help to reduce melanogenesis process and downregulate hyperpigmentation. In this study, KA esters synthesized using RMIM have slightly greater scavenging activity than other KA esters that were previously reported in the literature [14]. Tyrosinase is known as copper-containing enzyme, thus the capability of KA and KA esters to chelate metal ions may chelate cooper in tyrosinase, changing its three-dimensional conformation to inhibit its enzymatic activity [11].
The cytotoxicity of KA and KA esters was investigated in this study. It was previously suggested that inhibition of upregulated tyrosinase enzyme in melanoma cells might inhibit cell proliferation of melanoma cells [42, 43]. This is due to the correlation of microphthalmia-associated transcription factor (MITF) and extracellular signal-regulated kinase (ERK) in the pigmentation, proliferation, and survival of melanocytes and melanoma [23, 26, 35]. Due to this reason, it was expected that the inhibition of MITF expression may also inhibit melanoma cells proliferation. However, KA and KA esters were only known to inhibit melanogenesis by direct inhibition to tyrosinase and do not inhibit the expression of the transcription factor [5]. Therefore, the melanoma cells can still proliferate but the tyrosinase produced are not functional due to inhibition of KA and KA esters. In another study, $\alpha$-melanocyte-stimulating hormone (MSH) decreased a critical mediator in the tumorigenesis (syndecan-2 expression), melanoma cell migration, and invasion in a melanin synthesis-independent manner [44]. Other depigmenting compound like hydroquinone, is a strong tyrosinase inhibitor with bleaching effect and exerted very high cytotoxicity at high concentrations [45]. Besides that, vitamin $\mathrm{C}$ and multivitamin showed satisfactory inhibitory effect in melanin content and tyrosinase activity at low concentrations, though it could be toxic at high concentrations [40]. KA was claimed to be nontoxic at doses below $100 \mu \mathrm{g} / \mathrm{mL}[18,27,46]$. KA esters derived in this study have very low cytotoxicity, even at very high doses (up to $500 \mu \mathrm{g} / \mathrm{L}$ ). In summary, results from this study indicated that $\mathrm{KA}$ and KA esters are potential depigmenting agents with low cytotoxicity for application in cosmetic and skin-care products.

\section{Conclusion}

KA esters derived from esterification of KA and palm oil based fatty acid have been demonstrated as a safe and nontoxic depigmenting agents with a satisfactory inhibitory effect on melanin formation and tyrosinase activity as determined on $\alpha$-MSH induced B16F1 melanoma cells. Thus, it can be suggested that these depigmenting compounds have potential to be used in cosmetic formulations and to treat hyperpigmentation.

\section{Acknowledgment}

This paper was financially supported by CRDF-MTDC Grant from Malaysian Technology Development Corporation. A. F. B. Lajis is a postgraduate student funded by Graduate Research Fund (GRF) of Universiti Putra Malaysia and Mybrain 15 from Ministry of Higher Education of Malaysia.

\section{References}

[1] E. A. Hurst, J. W. Harbour, and L. A. Cornelius, "Ocular melanoma: a review and the relationship to cutaneous melanoma," Archives of Dermatology, vol. 139, no. 8, pp. 1067-1073, 2003.

[2] H. P. Huang, Y. W. Shih, Y. C. Chang, C. N. Hung, and C. J. Wang, "Chemoinhibitory effect of mulberry anthocyanins 
on melanoma metastasis involved in the Ras/PI3K pathway," Journal of Agricultural and Food Chemistry, vol. 56, no. 19, pp. 9286-9293, 2008.

[3] V. J. Hearing, "The expanding role and presence of neuromelanins in the human brain - why gray matter is gray," Pigment Cell and Melanoma Research, vol. 22, no. 1, pp. 10-11, 2009.

[4] J. P. Ortonne and D. L. Bissett, "Latest insights into skin hyperpigmentation," Journal of Investigative Dermatology Symposium Proceedings, vol. 13, no. 1, pp. 10-14, 2008.

[5] G. Eisenhofer, H. Tian, C. Holmes, J. Matsunaga, S. RofflerTarlov, and V. J. Hearing, "Tyrosinase: a developmentally specific major determinant of peripheral dopamine," The FASEB Journal, vol. 17, no. 10, pp. 1248-1255, 2003.

[6] S. J. Heo, S. C. Ko, S. M. Kang et al., "Inhibitory effect of diphlorethohydroxycarmalol on melanogenesis and its protective effect against UV-B radiation-induced cell damage," Food and Chemical Toxicology, vol. 48, no. 5, pp. 1355-1361, 2010.

[7] U. Panich, K. Kongtaphan, T. Onkoksoong et al., "Modulation of antioxidant defense by Alpinia galanga and Curcuma aromatica extracts correlates with their inhibition of UVAinduced melanogenesis," Cell Biology and Toxicology, vol. 26, no. 2, pp. 103-116, 2010.

[8] L. Novellino, A. Napolitano, and G. Prota, "5,6-Dihydroxyindoles in the fenton reaction: a model study of the role of melanin precursors in oxidative stress and hyperpigmentary processes," Chemical Research in Toxicology, vol. 12, no. 10, pp. 985-992, 1999.

[9] Y. Niwa and H. Akamatsu, "Kojic acid scavenges free radicals while potentiating leukocyte functions including free radical generation," Inflammation, vol. 15, no. 4, pp. 303-315, 1991.

[10] M. Springer, K. Engelhart, and H. K. Biesalski, "Effects of 3-isobutyl-1-methylxanthine and kojic acid on cocultures and skin equivalents composed of HaCat cells and human melanocytes," Archives of Dermatological Research, vol. 295, no. 2, pp. 88-91, 2003.

[11] R. Mohamad, M. S. Mohamad, N. Suhaili, M. M. Salleh, and A. B. Ariff, "Kojic acid: applications and development of fermention process for production," Biological and Molecular Biology Reviews, vol. 5, no. 2, pp. 24-37, 2010.

[12] S. E. Ashari, R. Mohamad, A. Ariff, M. Basri, and A. B. Salleh, "Optimization of enzymatic synthesis of palm-based kojic acid ester using response surface methodology," Journal of Oleo Science, vol. 58, no. 10, pp. 501-510, 2009.

[13] K. J. Liu and J. F. Shaw, "Lipase-catalyzed synthesis of kojic acid esters in organic solvents," Journal of the American Oil Chemists' Society, vol. 75, no. 11, pp. 1507-1511, 1998.

[14] T. Raku and Y. Tokiwa, "Regioselective synthesis of kojic acid esters by Bacillus subtilis protease," Biotechnology Letters, vol. 25, no. 12, pp. 969-974, 2003.

[15] H. S. Rho, H. S. Baek, S. M. Ann, D. H. Kim, and I. S. Chang, "Synthesis of new anti-melanogenic compounds containing two molecules of kojic acid," Bulletin of the Korean Chemical Society, vol. 29, no. 8, pp. 1569-1571, 2008.

[16] R. Mohamad and A. B. Ariff, "Biotransformation of various carbon sources to kojic acid by cell-bound enzyme system of A. flavus Link 44-1," Biochemical Engineering Journal, vol. 35, no. 2, pp. 203-209, 2007.

[17] N. H. Khamaruddin, M. Basri, G. E. C. Lian et al., "Enzymatic synthesis and characterization of palm-based kojic acid Ester," Journal of Oil Palm Research, vol. 20, pp. 461-469, 2009.

[18] S. Momtaz, B. M. Mapunya, P. J. Houghton et al., "Tyrosinase inhibition by extracts and constituents of Sideroxylon inerme L. stem bark, used in South Africa for skin lightening," Journal of Ethnopharmacology, vol. 119, no. 3, pp. 507-512, 2008.
[19] S. Shibata, S. Okano, Y. Yonemitsu et al., "Induction of efficient antitumor immunity using dendritic cells activated by recombinant Sendai virus and its modulation by exogenous IFN- $\beta$ gene," Journal of Immunology, vol. 177, no. 6, pp. 3564$3576,2006$.

[20] X. G. Cao, X. X. Li, Y. Z. Bao, N. Z. Xing, and Y. Chen, "Responses of human lens epithelial cells to quercetin and DMSO," Investigative Ophthalmology and Visual Science, vol. 48, no. 8, pp. 3714-3718, 2007.

[21] S. Makpol, N. N. M. Arifin, Z. Ismail, K. H. Chua, Y. A. M. Yusof, and W. Z. W. Ngah, "Modulation of melanin synthesis and its gene expression in skin melanocytes by palm tocotrienol rich fraction," African Journal of Biochemistry Research, vol. 3, no. 12, pp. 385-392, 2009.

[22] S. W. Choi, S. K. Lee, E. O. Kim et al., "Antioxidant and antimelanogenic activities of polyamine conjugates from corn bran and related hydroxycinnamic acids," Journal of Agricultural and Food Chemistry, vol. 55, no. 10, pp. 3920-3925, 2007.

[23] Y. J. Shin, C. S. Han, C. S. Lee et al., "Zeolite 4A, a synthetic silicate, suppresses melanogenesis through the degradation of microphthalmia-associated transcription factor by extracellular signal-regulated kinase activation in B16F10 melanoma cells," Biological and Pharmaceutical Bulletin, vol. 33, no. 1, pp. 72-76, 2010.

[24] Y. Aoki, T. Tanigawa, H. Abe, and Y. Fujiwara, "Melanogenesis inhibition by an oolong tea extract in B16 mouse melanoma cells and UV-induced skin pigmentation in brownish guinea pigs," Bioscience, Biotechnology and Biochemistry, vol. 71, no. 8, pp. 1879-1885, 2007.

[25] J. S. Yu and A. K. Kim, "Effect of combination of taurine and azelaic acid on antimelanogenesis in murine melanoma cells," Journal of Biomedical Science, vol. 17, supplement 1, article S45, 2010.

[26] D. S. Kim, S. H. Park, S. B. Kwon, K. Li, S. W. Youn, and K. C. Park, "(-)-Epigallocatechin-3-gallate and hinokitiol reduce melanin synthesis via decreased MITF production," Archives of Pharmacal Research, vol. 27, no. 3, pp. 334-339, 2004.

[27] S. K. Ha, M. Koketsu, K. Lee et al., "Inhibition of tyrosinase activity by N,N-unsubstituted selenourea derivatives," Biological and Pharmaceutical Bulletin, vol. 28, no. 5, pp. 838-840, 2005.

[28] Y. J. Kim, "Antimelanogenic and antioxidant properties of gallic acid," Biological and Pharmaceutical Bulletin, vol. 30, no. 6, pp. 1052-1055, 2007.

[29] K. D. Kim, M. H. Song, E. K. Yum, O. S. Jeon, Y. W. Ju, and M. S. Chang, "Melanogenesis inhibition by mono-hydroxycinnamic ester derivatives in B16 melanoma cells," Bulletin of the Korean Chemical Society, vol. 31, no. 1, pp. 181-184, 2010.

[30] M. Kinoshita, N. Hori, K. Aida, T. Sugawara, and M. Ohnishi, "Prevention of melanin formation by yeast cerebroside in B16 mouse melanoma cells," Journal of Oleo Science, vol. 56, no. 12, pp. 645-648, 2007.

[31] K. Sato, H. Takahashi, R. Iraha, and M. Toriyama, "Downregulation of tyrosinase expression by acetylsalicylic acid in murine B16 melanoma," Biological and Pharmaceutical Bulletin, vol. 31, no. 1, pp. 33-37, 2008.

[32] S. A. Burchill, D. C. Bennett, A. Holmes, and A. J. Thody, "Tyrosinase expression and melanogenesis in melanotic and amelanotic B16 mouse melanoma cells," Pathobiology, vol. 59, no. 5, pp. 335-339, 1991.

[33] T. Shioda, M. H. Fenner, and K. J. Isselbacher, "msg1, a novel melanocyte-specific gene, encodes a nuclear protein and is associated with pigmentation," Proceedings of the National 
Academy of Sciences of the United States of America, vol. 93, no. 22, pp. 12298-12303, 1996.

[34] K. Sato and M. Toriyama, "Depigmenting effect of catechins," Molecules, vol. 14, no. 11, pp. 4425-4432, 2009.

[35] C. Bertolotto, K. Bille, J. P. Ortonne, and R. Ballotti, "Regulation of tyrosinase gene expression by cAMP in B16 melanoma cells involves two CATGTG motifs surrounding the TATA box: implication of the microphthalmia gene product," Journal of Cell Biology, vol. 134, no. 3, pp. 747-755, 1996.

[36] D. Rusciano, P. Lorenzoni, and M. M. Burger, "Regulation of cmet expression in B16 murine melanoma cells by melanocyte stimulating hormone," Journal of Cell Science, vol. 112, no. 5, pp. 623-630, 1999.

[37] K. Ohguchi, Y. Banno, Y. Akao, and Y. Nozawa, "Involvement of phospholipase D1 in melanogenesis of mouse B16 melanoma cells," Journal of Biological Chemistry, vol. 279, no. 5, pp. 3408-3412, 2004.

[38] S. E. Hill, J. Buffey, A. J. Thody, I. Oliver, S. S. Bleehen, and S. MacNeil, "Investigation of the regulation of pigmentation in alpha-melanocyte-stimulating hormone responsive and unresponsive cultured B16 melanoma cells," Pigment Cell Research, vol. 2, no. 3, pp. 161-166, 1989.

[39] U. D. P. Lam, D. N. Hoang, H. B. Lee et al., "Depigmenting effect of Sterculia lynchnophera on B16F10 melanoma and C57BL/6 melan-a cells," Korean Journal of Chemical Engineering, vol. 28, no. 4, pp. 1074-1077, 2011.

[40] Y. K. Choi, Y. K. Rho, K. H. Yoo et al., "Effects of vitamin C vs. multivitamin on melanogenesis: comparative study in vitro and in vivo," International Journal of Dermatology, vol. 49, no. 2, pp. 218-226, 2010.

[41] I. Gülçin, "The antioxidant and radical scavenging activities of black pepper (Piper nigrum) seeds," International Journal of Food Sciences and Nutrition, vol. 56, no. 7, pp. 491-499, 2005.

[42] N. M. Vad, P. K. Kandala, S. K. Srivastava, and M. Y. Moridani, "Structure-toxicity relationship of phenolic analogs as antimelanoma agents: an enzyme directed prodrug approach," Chemico-Biological Interactions, vol. 183, no. 3, pp. 462-471, 2010.

[43] H. L. Ma, M. J. Whitters, R. F. Konz et al., "IL-21 activates both innate and adaptive immunity to generate potent antitumor responses that require perforin but are independent of IFN$\gamma$," Journal of Immunology, vol. 171, no. 2, pp. 608-615, 2003.

[44] J. H. Lee, H. Park, H. Chung et al., "Syndecan-2 regulates the migratory potential of melanoma cells," Journal of Biological Chemistry, vol. 284, no. 40, pp. 27167-27175, 2009.

[45] Z. M. Hu, Q. Zhou, T. C. Lei, S. F. Ding, and S. Z. Xu, "Effects of hydroquinone and its glucoside derivatives on melanogenesis and antioxidation: biosafety as skin whitening agents," Journal of Dermatological Science, vol. 55, no. 3, pp. 179-184, 2009.

[46] S. H. Lee, S. Y. Choi, H. Kim et al., "Mulberroside F isolated from the leaves of Morus alba inhibits melanin biosynthesis," Biological and Pharmaceutical Bulletin, vol. 25, no. 8, pp. 10451048, 2002. 


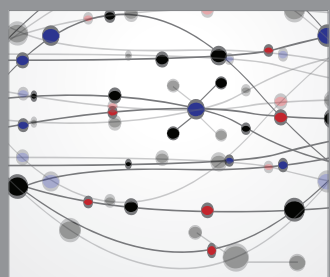

The Scientific World Journal
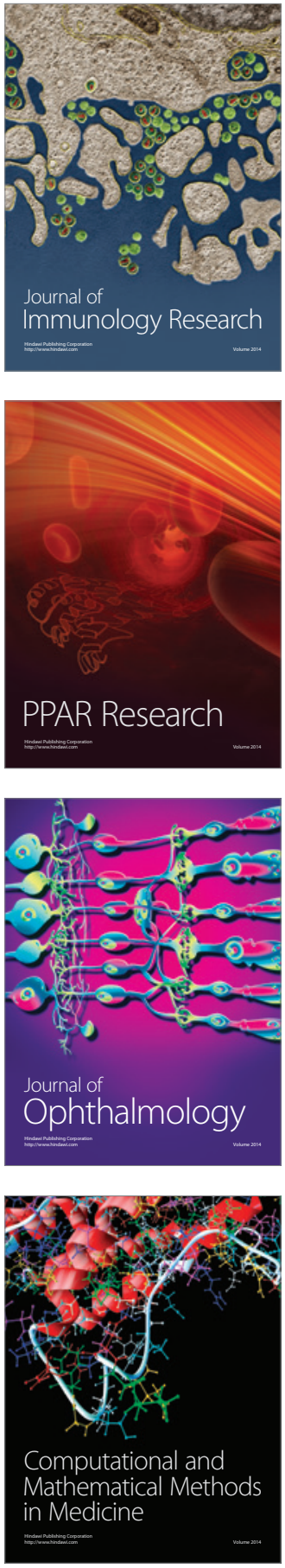

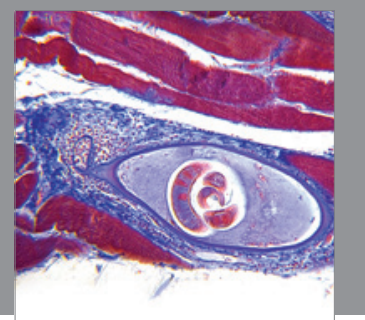

Gastroenterology

Research and Practice
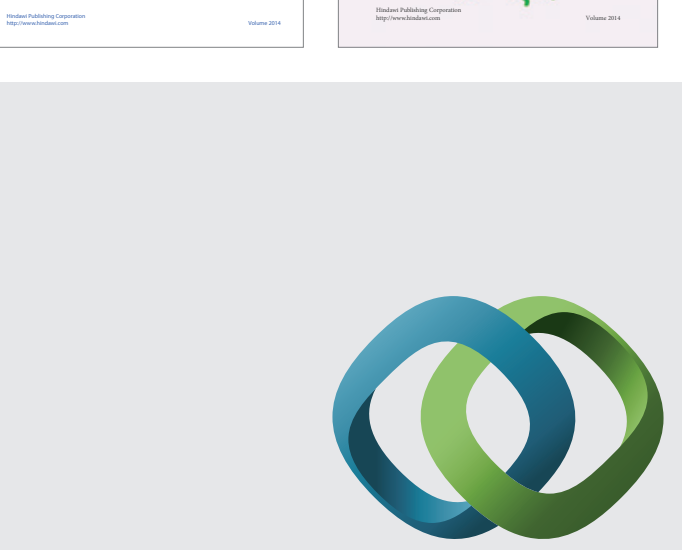

\section{Hindawi}

Submit your manuscripts at

http://www.hindawi.com
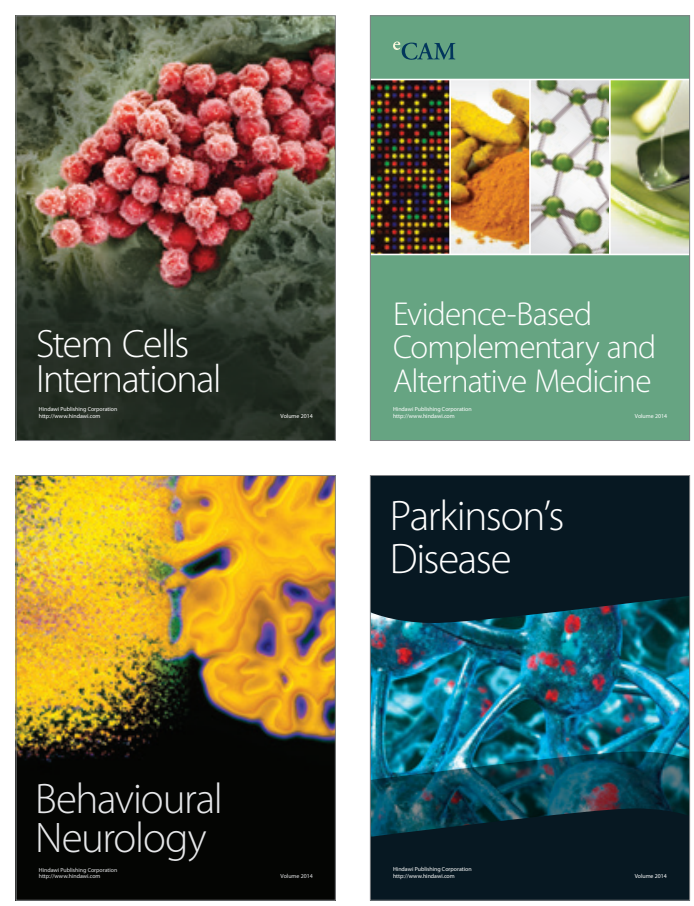

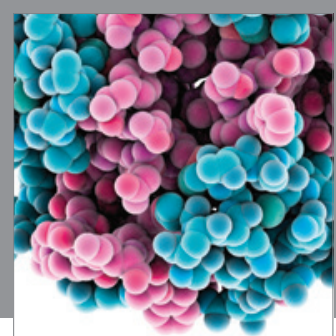

Journal of
Diabetes Research

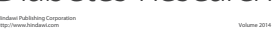

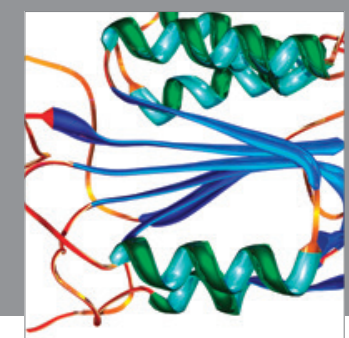

Disease Markers
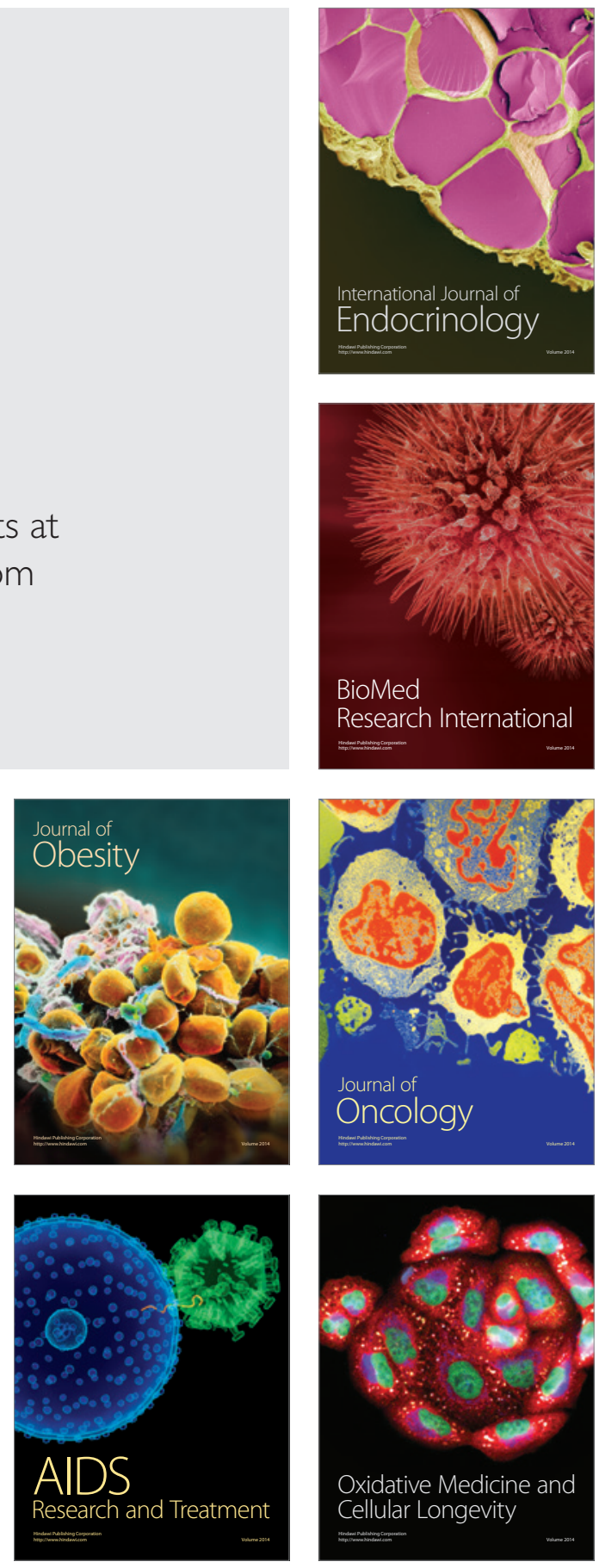